\title{
Single-Phase Series Active Conditioner for the Compensation of Voltage Harmonics, Sags, Swell and Flicker
}

\author{
H. Carneiro, J.G. Pinto, J. L. Afonso \\ University of Minho - Industrial Electronics Department, Campus de Azurém 4800-058 - Guimarães, \\ Portugal. \\ E-mail:1hcarneiro@dei.uminho.pt,.gpinto@dei.uminho.pt,.jla@dei.uminho.pt
}

\begin{abstract}
Simulation and experimental results shown on this paper describes the performance of a developed Single-Phase Series Active Conditioner that regulates the voltage being delivered to a load. This Custom Power device is a solution for power quality issues related with voltage amplitude variations, which are responsible for innumerous flaws in industrial processes which brings with it high financial losses. The SinglePhase Series Active Conditioner is a back-to-back converter, composed by two power converters sharing a common DC link. One of the converters is series connected to the electrical grid, whereas the other one is shunt connected. The first is used to compensate load voltage, and the second to regulate the DC link voltage. This paper shows the results obtained with the Series Active Conditioner in Sag, Swell and Flicker events, and also Voltage Harmonics compensation, in order to deliver to the load a sinusoidal voltage, at nominal amplitude.
\end{abstract}

\section{INTRODUCTION}

Voltage amplitude variations are Power Quality problems that interfere severely with several manufacturing processes in industry. The most severe is a prolonged interruption, which can cause vast financial losses [1]. However, nowadays these situations are not very frequent. Voltage sags, instead, are very frequent, and end up being more costly to companies [1][2]. Voltage swells are less frequent, and are often associated with the removal of big loads from the electrical system, or to the connection of large capacitor banks to it [3]. Although swell events are rare, they can result in equipment malfunction and permanent damage. The effects of voltage swells are not so well studied as the ones caused by voltage sags. However, one of the most significant is the possibility of power transformers enter in magnetic flux saturation during swell, leading to a high electromagnetic stress [4]. According the IEEE 1159-2009 Standard, "a sag is a decrease in RMS voltage to between $0.1 \mathrm{pu}$ and $0.9 \mathrm{pu}$ for durations from 0.5 cycles to $1 \mathrm{~min}$ "[3], whereas the swell is "an increase in rms voltage above $1.1 \mathrm{pu}$ for durations from 0.5 cycle to $1 \mathrm{~min}$ ".

Another voltage variation phenomenon is the one usually known as flicker, due to the effect caused by it on the lighting intensity. This phenomena is named by the IEEE 1159-2009 Standard as "Voltage Fluctuation" and is described as "systematic variations of the voltage envelope or a series of random voltage changes, the magnitude of which does not normally exceed the voltage ranges (...) of $0.95 \mathrm{pu}$ to 1.05 pu" [3]. It is caused mainly by arc furnaces and can be described as similar to an amplitude modulation of the fundamental frequency, as in an A.M. radio signal [3]. The effect caused in the lighting system produces discomfort, since it is perceived by the human visual system [5].

On the other hand, the wide use of non-linear loads on the nowadays industrial and domestic applications led to a harmonic distorted current consumption. These harmonic currents cause harmonic voltage drops on the electrical system's impedances, thus degrading the system's voltages waveforms. The harmonically distorted voltage can cause several issues, as increased mechanical stress in electrical motors or malfunction on electronic devices [6].

The Power Quality issues here exposed can be mitigated by a Single-Phase Series Active Conditioner. The aim of this custom power device is to synthesize a voltage that, added to the system's voltage, allows that the load is supplied by a sinusoidal voltage, at nominal amplitude.

The developed Single-Phase Series Active Conditioner is composed by two power converters, back-to-back connected and with a common DC link. One of the converters, series connected to the electrical grid, is responsible for the compensation of the load voltage. The other converter, shunt connected to the electrical grid, deals with the regulation of the DC link voltage. In this paper are presented simulation and experimental results of this device, compensating of Voltage Sags, Swells and Flicker, as well as Voltage Harmonics.

\section{SYSTEM OVERVIEW}

The power converters aforementioned are H-Bridge converters with 4 IGBTs. The Series Converter is directly connected to the power system, with no coupling transformer, using only a passive filter to attenuate switching noise from the compensation voltage. On the other hand, the Shunt Converter is coupled to the electrical System via a step-up transformer. That implies that the DC link voltage, to allow the injection of currents in the electrical system, can be lower. This increases the controllability of the Series Converter, since the DC link voltage level is closer to the levels that the Series Converter aims to compensate. There is also a passive filter on the Shunt Converter side, as well used to attenuation of switching noise. The passive filters on both converters are tuned to $16 \mathrm{kHz}$, which is the switching frequency of the 


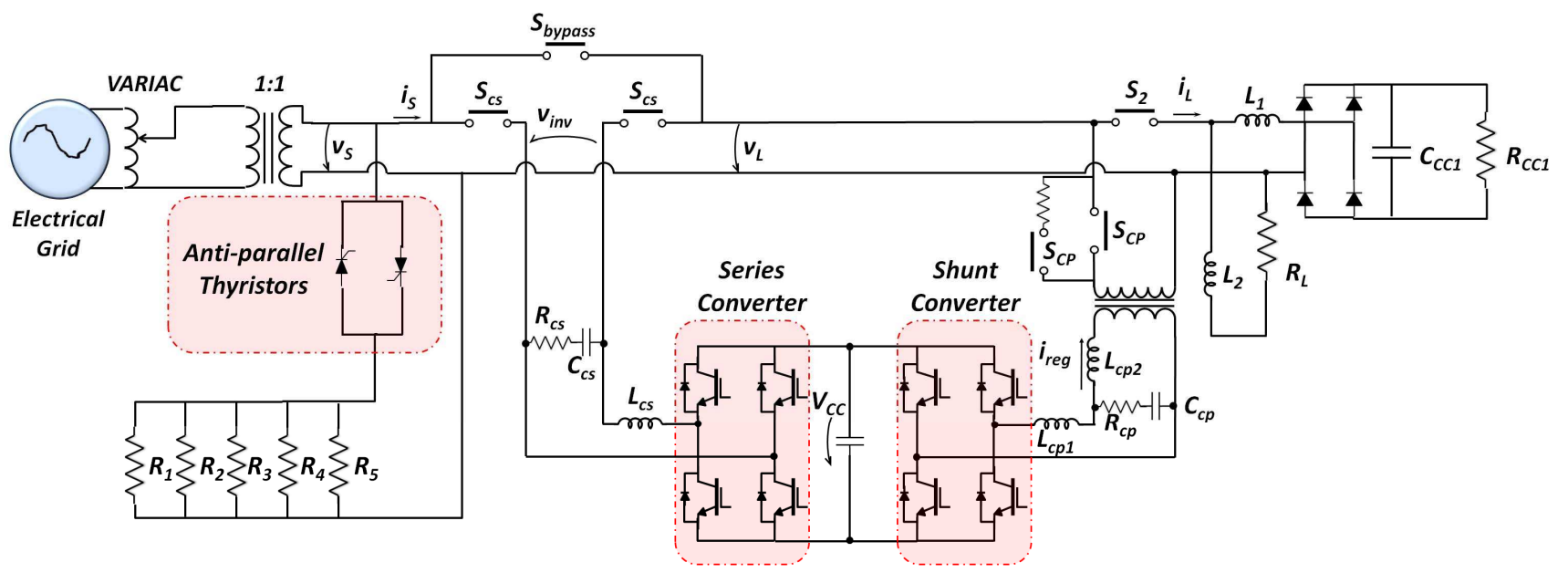

Fig. 1. Electrical Diagram of the Single-Phase Back-to-Back Converter.

coverters. The design of these passive filters is simplified by the use of a PWM switching technique, which is a fixed frequency one.

The load is non-linear, composed by a single-phase rectifier with $\mathrm{RC}$ circuit at the DC side, and with a smoothing inductor at its input. In parallel with this rectifier, there is also a RL circuit. In order to emulate voltage variations, it was used a VARIAC (variable autotransformer) and 5 resistors that are connected to the electrical system by anti-parallel thyristors. This emulation circuit will be the scope of further explanation in item V. In Fig. 1 the developed system is displayed, where it can also be seen an isolation transformer between the VARIAC and the Series Active Converter, placed to provide galvanic isolation from the electrical grid.

\section{Control of the Single-Phase SERIES ACTIVE CONDITIONER}

The controller of the Series Active can be divided in two main blocks. The one that controls the Shunt Converter is the Current Reference Algorithm, whereas the one that controls the Series Converter is the Voltage Reference Algorithm. Both algorithms are based in concepts of the well known $p-q$ Theory [7], and in the use of a PLL (Phase-Locked Loop) algorithm that tracks the fundamental component of the source voltage [8]. The controller of the Series Active Conditioner is represented in Fig. 2, and is presented with more detail in [8].

As there is no power source on the DC link of the Series Active Conditioner, the Shunt Converter must be controlled in order to regulate the DC link voltage. The Current Reference Algorithm computes the reference current for the Shunt Converter, and ensures that this current, used only to regulate the DC link voltage, is sinusoidal and in phase with the source voltage. This way, the current of the Shunt Converter will not augment the harmonic currents at the system, and thus, it will not increase voltage harmonic distortion, and it is also ensured that the Shunt Converter only drains active power from the source.

The measurement of the DC link voltage is fed into a lowpass filter, being the output $\left(v_{D C}\right)$ of the filter used for the calculation of the control signal $p_{\text {Reg }}$ :

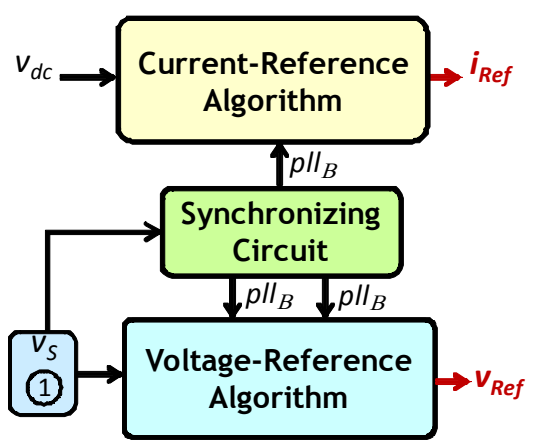

Fig. 2. Single-Phase Series Active Conditioner Controller.

$$
p_{\operatorname{Reg}}=\left(v_{\text {Ref_DC }}-v_{D C}\right) \cdot\left(k_{p_{-} d c}\right) .
$$

The instantaneous regulation power, $p_{\text {reg }}$, can be understood as the amount of energy per unit of time that is drained or injected by the Shunt Converter in order to keep the DC link voltage regulated. The reference is given by $v_{R e f D C} . K_{p_{-} d c}$ is the proportional gain of a Proportional Controller.

The next stage is to extract the instantaneous values of the reference currents in the $\alpha-\beta$ reference frame, since the algorithm is based on the $p-q$ Theory. This is made as follows:

$$
\left[\begin{array}{c}
i_{R e f_{-} \alpha} \\
i_{\text {Ref } \beta}
\end{array}\right]=\frac{1}{p l l_{\alpha}^{2}+p l l_{\beta}^{2}} \cdot\left[\begin{array}{cc}
p l l_{\alpha} & p l l_{\beta} \\
p l l_{\beta} & -p l l_{\alpha}
\end{array}\right] \cdot\left[\begin{array}{c}
p_{\text {Reg }} \\
0
\end{array}\right],
$$

where $p l l_{\alpha}$ is the fundamental component of the source voltage, and $p l l_{B}$ is $\mathrm{pll}_{\alpha}$ delayed by $90^{\circ}$.

Using the Inverse Clarke Transformation [9], and assuming a fictitious three-phase three-wire system, the reference current to be synthesized by the Shunt Converter, $i_{R e f}$ is :

$$
\left[\begin{array}{c}
i_{\text {Ref }} \\
0 \\
0
\end{array}\right]=\sqrt{\frac{2}{3}} \cdot\left[\begin{array}{cc}
1 & 0 \\
-1 / 2 & \sqrt{3} / 2 \\
-1 / 2-\sqrt{3} / 2
\end{array}\right] \cdot\left[\begin{array}{c}
i_{\text {Ref }} \alpha \\
i_{\text {Ref }} \beta
\end{array}\right] .
$$

Ultimately, it can be simplified in a way that: 


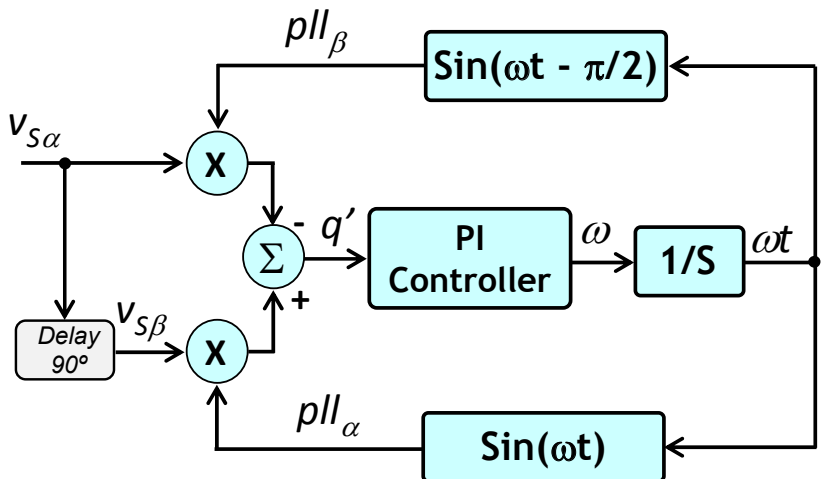

Fig. 3. Single-phase Phase-Locked-Loop.

$$
i_{\text {Ref }}=\sqrt{\frac{2}{3}} \cdot\left(p l l_{\alpha} \cdot p_{\text {Reg }}\right) .
$$

The variable $i_{R e f}$ is produced in phase with the fundamental component os the systems voltage, and is sinusoidal, being its amplitude determined by $p_{\text {Reg. }}$. The filtered variable $v_{D C}$ avoids that the voltage ripple present in the DC link, as other sudden voltage variations, are propagated to $p_{\text {reg }}$ and, consequently, to $i_{R e f}$, assuring that no harmonic content is present on this variable. Therefore, the Shunt Converter does not contribute to the harmonic content of the source voltage.

The Voltage Reference Algorithm is simple, since it is based on a direct comparison between signals. The signal $v_{S}$, represented in Fig. 2, is measured from the electrical system, and is then compared with $p_{l} l_{\alpha}$, which has the fundamental component of $v_{S}$, at nominal amplitude. The difference between these two signals is the voltage to be synthesized by the Series Converter, that is:

$$
v_{\operatorname{Re} f}=p l l_{\alpha}-v_{S} .
$$

As it can be seen, the controller of the Series Active Conditioner is, conceptually, very simple. But it relies in a robust PLL scheme, which comprises long processing times. The proposed PLL scheme is Single-Phase PLL, presented in [8] and depicted in Fig. 3.

\section{Simulation Results}

Simulation results were obtained for each of three amplitude variation Power Quality events. Harmonic (sag, swell and flicker) distortion is present in each and every event simulated.

\section{A. Sag}

Simulation results obtained during a sag condition are depicted in Fig. 4 and Fig. 5. Both of them represent the transient of sag start. Fig. 4 relates with the Series Converter, and it can be seen that the load voltage $\left(v_{L}\right)$ is kept constant as the source voltage $\left(v_{S}\right)$ drops. This is due to the fast response of a direct comparison algorithm, which is confirmed by the correct tracking preformed by the compensation voltage $\left(v_{i n v}\right)$ to the reference voltage $\left(v_{R e f}\right)$. At the beginning of the sag, the source voltage $\left(v_{S}\right)$ suffers an RMS value drop from $115 \mathrm{~V}$ to $92 \mathrm{~V}$, while the load voltage $\left(v_{L}\right)$ RMS value is kept at $115 \mathrm{~V}$.

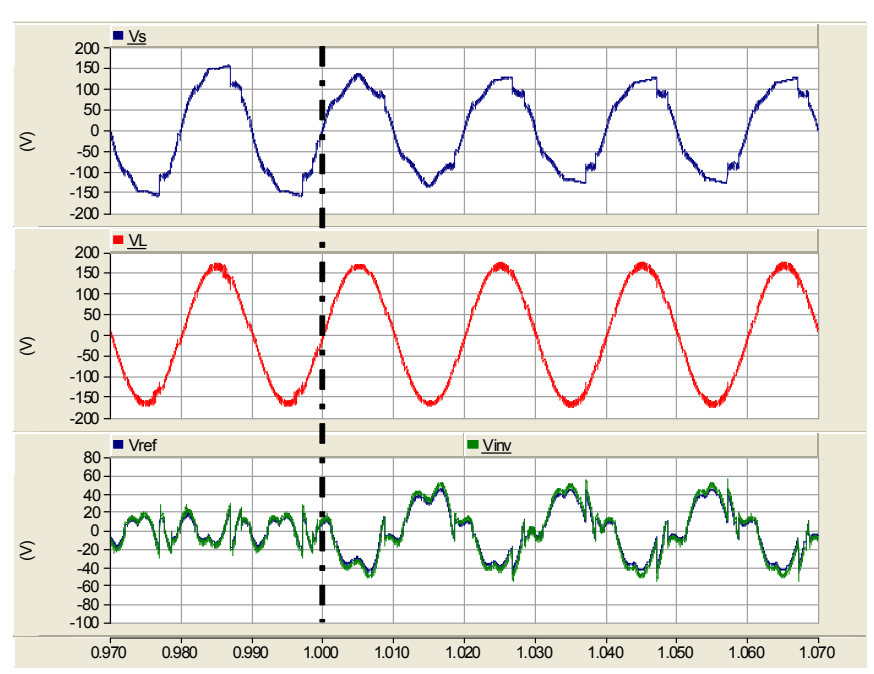

Fig. 4. Source voltage (top), load voltage (middle), reference $\left(v_{r e f}\right)$ and produced compensationvoltage $\left(v_{i n v}\right)$, during a sag transient. The dotted line indicates the start of the event.

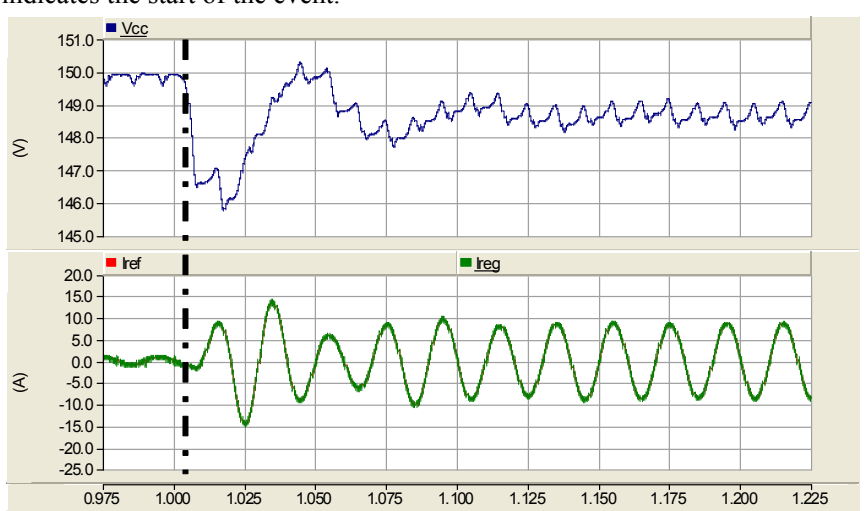

Fig. 5. DC link voltage (top), reference $\left(i_{r e f}\right)$ and consumed current by the Shunt Converter $\left(i_{\text {reg }}\right)$, during a sag transient. The dotted line indicates the start of the event.

This means that the Series Active Conditioner compensated a $20 \%$ sag.

It can also be seen that the source voltage is harmonic polluted before and during the sag, whereas the load voltage presents an almost sinusoidal waveform. The THD (Total Harmonic Distortion) of $v_{S}$ is of $9.7 \%$, but the THD of $v_{L}$ is kept at 1.4\%, which complies with ANSI/IEEE 519-1992 Standard [10], and with IEC 61000-2-4 Regulation for industrial environment harmonic distortion [11].

Fig 5 shows the action preformed by the Shunt Converter when the sag event occurs. When the DC link voltage $\left(v_{D C}\right)$ starts to fall, the Shunt Converter increases the current consumption, thus making available the amount of power needed by the Series Converter to compensate the sag. Also, it is shown that the reference current $\left(i_{R e f}\right)$ computed by the Reference Current Algorithm is well tracked by the regulation current $\left(i_{\text {reg }}\right)$.

\section{B. Swell}

As for what happens during a swell event, one can see in Fig. 6 the simulation result of the swell transient, where it can be seen that, as in the previous sag event, $v_{L}$ is kept constant during the swell event. This event consists in a $v_{S}$ RMS value increase from $115 \mathrm{~V}$ to $144 \mathrm{~V}$, which corresponds to a $25 \%$ 


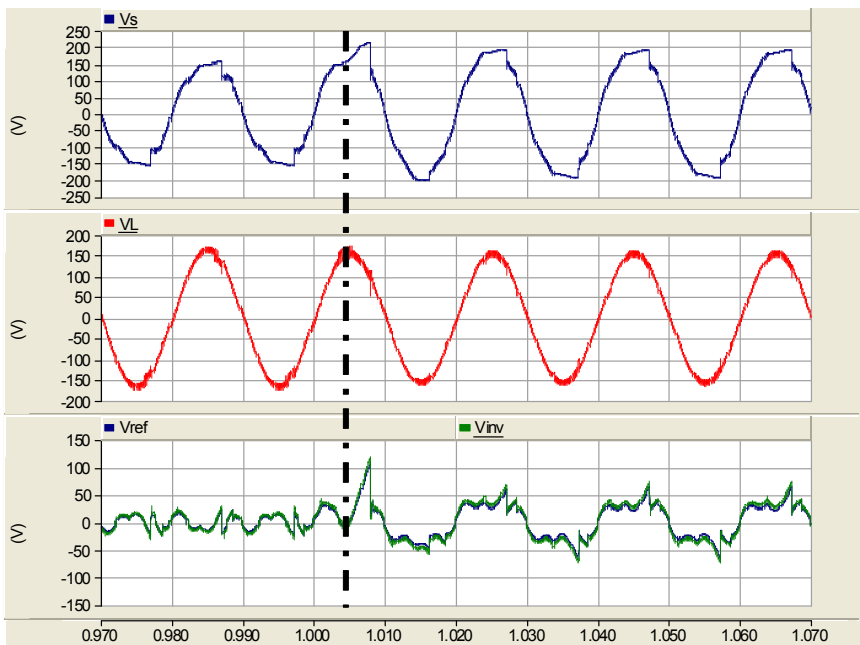

Fig. 6. Source voltage (top), load voltage (middle), reference $\left(v_{r e f}\right)$ and produced voltage $\left(v_{\text {inv }}\right)$, during swell transient. The dotted line indicates the start of the event.

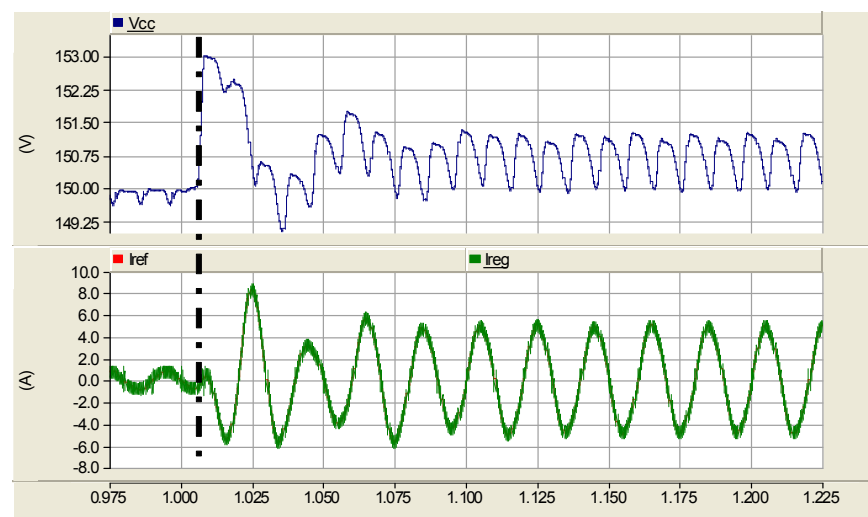

Fig. 7. DC link voltage (top), reference $\left(i_{\text {ref }}\right)$ and consumed current by the Shunt Converter $\left(i_{\text {reg }}\right)$, during sag transient. The dotted line indicates the start of the event.

swell. In the load side, $v_{L}$ RMS value is kept at $114 \mathrm{~V}$. As for the harmonic distortion, the THD of $v_{S}$ is of $9.7 \%$, and at load it is kept at $2 \%$ during the swell event, which comprises with the aforementioned standards and regulations.

In what concerns to the performance of the Shunt Converter, one can see in Fig. 7 its behavior and impact on the DC link voltage, $v_{D C}$. The dotted line represents the beginning of the event, and it can be seen that the power absorbed by the Series Converter for compensating $v_{L}$ reflects on $v_{D C}$, which suffers an increase. Then, the Shunt Converter starts to supply current to the electrical system to regulate $v_{D C}$. It can be seen that $i_{\text {reg }}$, shortly after the swell start, inverts its phase, thus inverting the power flow.

\section{Flicker}

The flicker event is characterized by its oscillating nature, as it was mentioned before. So, for its compensation, the Series Active Converter must adapt it compensation voltage to to these oscillations. In order to emulate flicker on the simulation model, $v_{S}$ RMS value was set to change 1.5 times per second from $113 \mathrm{~V}$ to $104 \mathrm{~V}$, which represents an amplitude variation of 7\%. These characteristics of the event comply with the IEEE 1559-2009 Standard [3]. During the event, as it can be seen in Fig. 8, the load voltage $\left(v_{L}\right)$ is kept

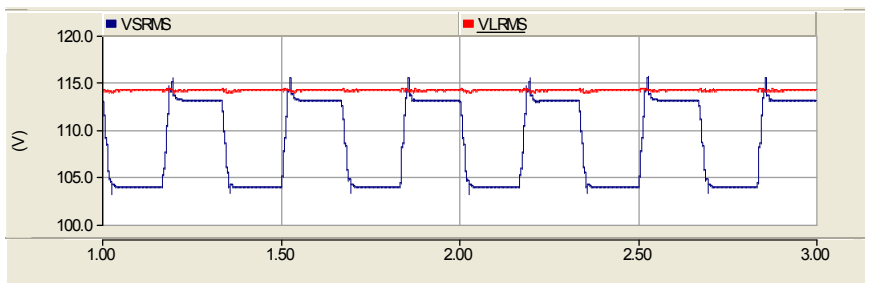

Fig. 8. RMS values o $v_{S}$ and $v_{L}$ during a flicker event, with the Series Active Conditioner.

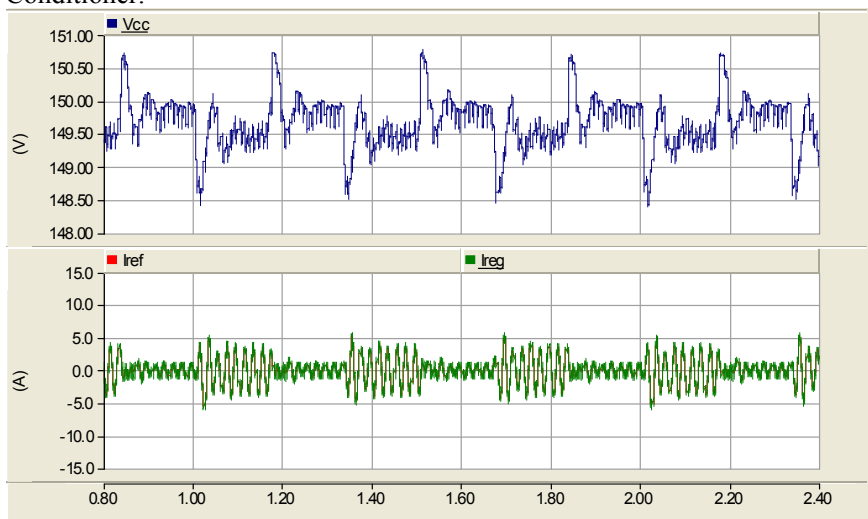

Fig. 9. DC link voltage (top), reference $\left(i_{r e f}\right)$ and consumed current by the Shunt Converter $\left(i_{\text {reg }}\right)$, during flicker.

constant at $114 \mathrm{~V}$. As for harmonic distortion, in $v_{L}$ the THD is compensated to $2 \%$, whereas at $v_{S}$ it is of $10 \%$.

The oscillating nature of the flicker event is also reflected on the DC link voltage. In fact, $v_{D C}$ also suffers some oscillation, given the different amount of power needed to compensate $v_{L}$ during $v_{S}$ oscillations. This means that the current absorbed by the Shunt Converter is also pulsating, but it always consumes current with a sinusoidal waveform. This can be seen in Fig. 9, following $i_{\text {reg }}$.

\section{EXPERIMENTAL RESULTS}

In Fig. 1 it is shown the electrical diagram of the SinglePhase Series Active Conditioner, as it was implemented. To emulate the voltage variation transients it was used a combined action between the VARIAC and the resistors $\mathrm{R}_{1}$ to $\mathrm{R}_{5}$, which are connected to the electrical system by an antiparallel thyristors controlled switch.

\section{A. $\quad$ Sag}

For the emulation of the sag event, the VARIAC was set to $115 \mathrm{~V}$, which is the nominal RMS value of $v_{s}$. To start the sag event, the anti-parallel thyritors are triggered, thus connecting the 5 resistors, each with $26.5 \Omega$. The current consumption of these resistors causes a voltage drop on the windings of the VARIAC, and of the isolation transformer, and also in the electrical grid line impedances, leaving $v_{S}$ with a RMS value of $88.9 \mathrm{~V}$, which corresponds to a $22.7 \%$ drop. Fig. 10 shows the performance of the Series Active Conditioner on the system's voltages, in a steady state regime. It can be seen that $v_{S}$ presents low amplitude and significant harmonic distortion, whereas $v_{L}$ is fairly compensated, either in amplitude, as in harmonic distortion. This can be confirmed by Fig. 11, where it can be seen the RMS values of both $v_{S}$ and $v_{L}$, as well as 


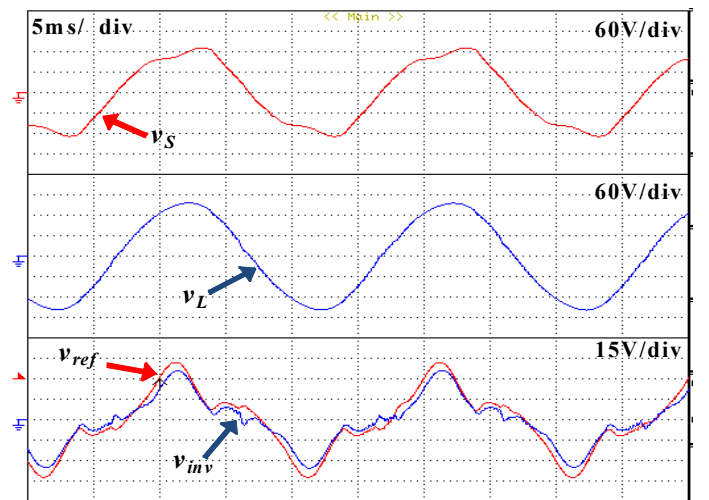

Fig. 10. Source voltage (top), load voltage (middle), reference $\left(v_{r e f}\right)$ and produced voltage $\left(v_{i n v}\right)$, during sag.

(a)

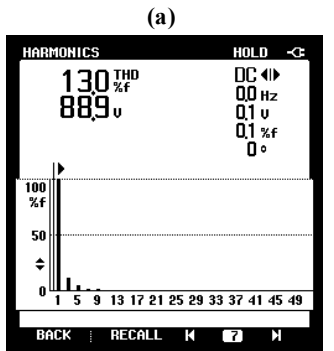

Fig. 11. RMS and harmonic distortion during sag: (a) of source voltage; (b) of load voltage.
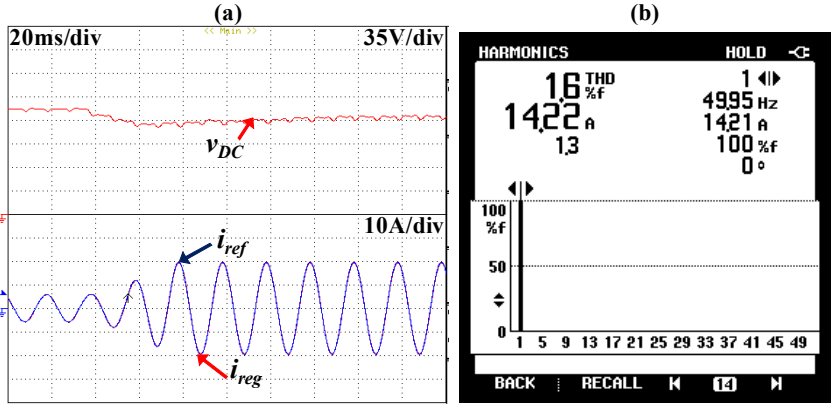

Fig. 12. Shunt Converter action: (a) DC link voltage, regulation current and respective reference; (b) THD and RMS value of the regulation voltage.

their THD values. These measurements indicate that the harmonic distortion complies either with the ANSI/IEEE 5191992 Standard, as with the IEC 61000-2-4 Regulation, which indicate a maximum limit of THD distortion to the voltage waveform of $5 \%$, having the compensated $v_{L}$ a THD value of only $3.8 \%$. Also the RMS value of the compensated load voltage is outside the limits imposed by the IEEE 1159-2009 standard to identify Power Quality Problems.

Finally, and in Fig. 12, it is shown the behavior of the Shunt Converter, increasing the consumption of current to ensure the necessary power to the Series Converter, so that it can compensate the voltage sag event. It can be seen that the consumption of current of the Shunt Converter is made with an almost sinusoidal waveform, with a THD of $1.6 \%$.

\section{B. Swell}

In order to emulate the Swell event, the resistors were initially connected to the electrical system, causing the previously referred voltage drop. However, at this point, the VARIAC was regulated in order to supply a nominal value of

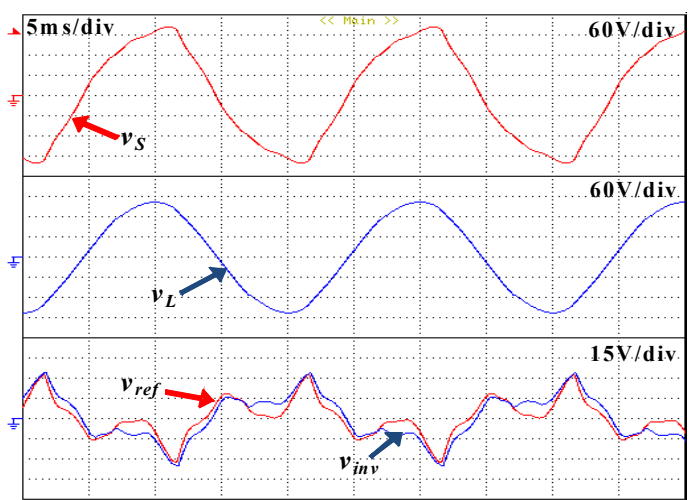

Fig. 13. Source voltage (top), load voltage (middle), reference $\left(v_{r e f}\right)$ and produced voltage $\left(v_{i n v}\right)$, during swell.
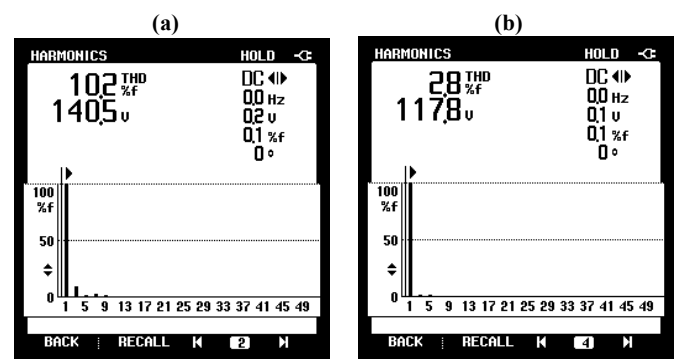

Fig. 14. RMS and harmonic distortion during swell: (a) of source voltage; (b) of load voltage.

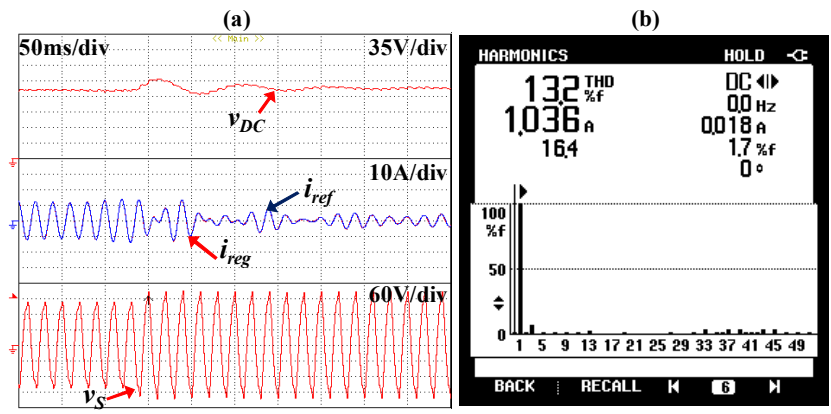

Fig. 15. Shunt Converter action: (a) DC link voltage, regulation current and respective reference and source voltage; (b) THD and RMS value of the regulation voltage.

source voltage $\left(v_{S}\right)$. This way, when the resistors are disconnected from the electrical system, a voltage swell occurs. This event is shown in Fig. 13, in its steady state regime, where it is perceptible the high voltage amplitude of $v_{S}$, which rises to $140.5 \mathrm{~V}$ (a $21 \%$ increase), of $v_{S}$, accompanied by significant harmonic distortion. By the action of the Series Active Conditioner, the load voltage $\left(v_{L}\right)$ presents a low THD and an amplitude close to nominal, as it can be confirmed in Fig. 14. It can be seen that the RMS value of the voltage delivered to the load comprises the limits stipulated by the aforementioned regulations and standards.

The action of the Shunt Converter is shown in Fig. 15. In this figure it is also represented $v_{S}$, so that it can be perceptible that, when the swell event starts, the current direction shifts, as the Series Converter starts to absorb power in order to compensate the load voltage, and the Shunt Converter regulates $v_{D C}$ by injecting current in the electrical system. In this condition, the current injected has low amplitude, just $1 \mathrm{~A}$, and has a THD of $13 \%$. This elevated 
THD value is caused by the difficulty of the Shunt Converter in Synthesize low amplitude current. However, this current does not affect $v_{S}$, since it is directly consumed by the load.

\section{Flicker}

For the emulation of flicker, the procedure was similar to the emulation of sag. The differences are in the number of resistors used, which were only 3 , and in that the thyristors where switched between on and off state 100 times per minute (1.67 times per second), thus emulating the flicker event.

In Fig. 16, it can be seen the variation of the RMS values of both $v_{S}$ and $v_{L}$, during the flicker event, and with the operation of the Series Active Conditioner. In Table I, the RMS values of both voltages are shown, either in the moments where $v_{S}$ is lower, either when it is near nominal amplitude. Even though $v_{L}$ still reflects some voltage oscillation, it is clearly mitigated, being limited between $114 \mathrm{~V}$ and $115 \mathrm{~V}$. In the same table is shown the THD in both circumstances, and $v_{L}$ total harmonic distortion is kept around 3\%. Under these measurements, it can be said that the $v_{L}$, under the compensation of the Series Active Conditioner the regulations and standards aforementioned are complied.

TABLE I

MEASURED SOURCE AND LOAD VOLTAGE RMS AND THD VALUES DURING FLICKER EVENT

\begin{tabular}{|c|c|c|c|}
\cline { 3 - 4 } \multicolumn{2}{c|}{} & Low Voltage & Nominal \\
\hline $\begin{array}{c}\text { Source Voltage } \\
\left(v_{S}\right)\end{array}$ & RMS & $102,2 \mathrm{~V}$ & $115,3 \mathrm{~V}$ \\
\cline { 2 - 4 } & THD & $12,8 \%$ & $13,2 \%$ \\
\hline $\begin{array}{c}\text { Load Voltage } \\
\left(v_{L}\right)\end{array}$ & RMS & $114 \mathrm{~V}$ & $115 \mathrm{~V}$ \\
\cline { 2 - 4 } & THD & $3,3 \%$ & $3 \%$ \\
\hline
\end{tabular}

The value of $i_{\text {reg }}$ increases and decreases according with the power needs of the Series Converter to compensate $v_{L}$. This can be seen in Fig. 17, where $i_{\text {reg }}$ is presented during flicker

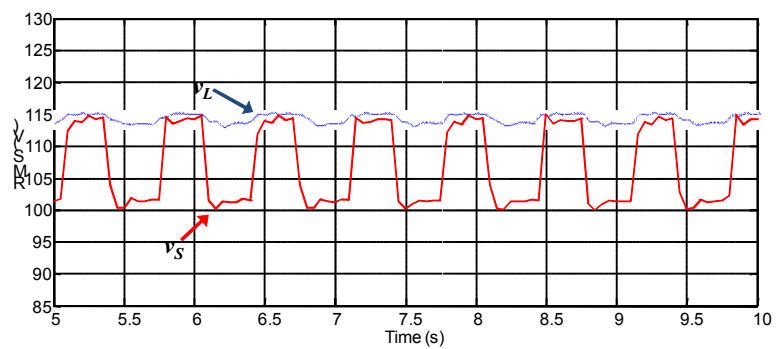

Fig. 16. RMS values o $v_{S}$ and $v_{L}$ during a flicker event, with the Series Active Conditioner.

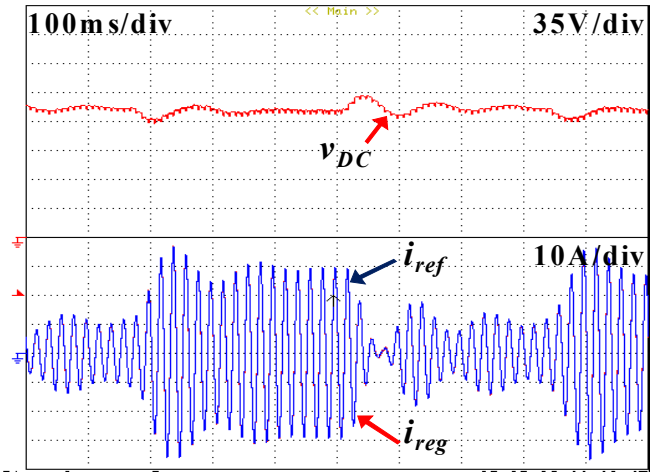

Fig. 17. DC link voltage (top), reference $\left(i_{r e f}\right)$ and consumed current by the Shunt Converter $\left(i_{\text {reg }}\right)$, during flicker. alongside with $v_{D C}$, which is kept regulated by the action of the Shunt Converter.

\section{CONCLUSIONS}

A Single-Phase Series Active Conditioner is presented as a custom power device focused in the compensation of Power Quality issues related with voltage amplitude and waveform. One of the key features for its performance is the combined action between both converters that compose the Series Active Conditioner. As the Series Converter compensates the voltage to be delivered to the load, the Shunt Converter ensures that the Series Converter has enough power to perform its task by regulating the DC link voltage.

It has been shown that the Single-Phase Series Active Conditioner can compensate loads from sag, swell, flicker and voltage harmonic distortion. The load voltage on each of the situations presented in this paper was compliant with IEEE Standards, as the IEEE 519-1992, and the ANSI/IEEE 1159-2009, and also with the IEC Regulation IEC 61000-2-4, thus reducing the risk of malfunction of sensitive loads, and increases their lifespan, minimizing risks of industrial process interruptions and averting all the resulting consequences.

\section{ACKNOWLEDGMENTS}

The Authors are grateful to FCT (Fundação para a Ciência $e$ Tecnologia) for funding the project PTDC/EEAEEL/104569/2008.

\section{REFERENCES}

[1] J.V. Milanovic and Y. Zhang, "Global Minimization of Financial Losses Due to Voltage Sags With FACTS Based Devices," IEEE Transactions on Power Delivery, vol. 25, 2010, pp. 298-306.

[2] C. Meyer, R.W. Doncker, Y.W. Li, and F. Blaabjerg, "Optimized Control Strategy for a Medium-Voltage DVR-Theoretical Investigations and Experimental Results," IEEE Transactions on Power Electronics, vol. 23, 2008, pp. 2746-2754.

[3] IEEE Std 1159 TM-2009, IEEE Recommended Practice for Monitoring Electric Power Quality, 2009.

[4] S. Choi, "A Generalized Voltage Compensation Strategy for Mitigating the Impacts of Voltage Sags/Swells," IEEE Transactions on Power Delivery, vol. 3, 2005, pp. 1762-2297.

[5] J. Ruiz, "A Review of Flicker Severity Assessment by the IEC Flickermeter," IEEE Transactions on Instrumentation and Measurement, vol. 64, 2010, pp. 4/1-2047.

[6] A.E. Emannuel, W.F. Horton, W.T. Jewel, and D.J. Phileggi, "Effects of Harmonics on Equipment Report of the IEEE Task Force on the Effects of Harmonics on Equipment," IEEE Transactions on Power Delivery, vol. 8, 1993.

[7] E.H. Watanabe, H. Akagi, and M. Aredes, "Instantaneous p-q power Theory for compensating nonsinusoidal systems," 2008 International School on Nonsinusoidal Currents and Compensation, Lagów: 2008, pp. 1-10.

[8] H. Carneiro, L.F. Monteiro, and J.L. Afonso, "Comparisons between synchronizing circuits to control algorithms for single-phase active converters," 2009 35th Annual Conference of IEEE Industrial Electronics, 2009, pp. 3229-3234.

[9] M. Manana Canteli, a. Ortiz Fernandez, L. Ignacio Eguiluz, and C. Renedo Estebanez, "Three-Phase Adaptive Frequency Measurement Based on Clarke's Transformation," IEEE Transactions on Power Delivery, vol. 21, 2006, pp. 1101-1105.

[10] "IEEE Std 519-1992 - IEEE Recommended Practices and Requirements for Harmonic Control in Electrical Power Systems," America, 1992.

[11] L. Asiminoaei, S. Hansen, and F. Blaabjerg, "Predicting Harmonics by Simulations . A Case Study for High Power Adjustable Speed Drives," Electrical Power Quality and Utilization Magazine, vol. II, 2006, pp. 65-76. 